Fecha de recepción: agosto 2008 Fecha de aceptación: marzo 2009 Versión final: diciembre 2010

\section{Turismo: portal de la diversidad cultural. El turismo receptivo como espacio para el encuentro multicultural}

Diego Navarro ${ }^{(*)}$

\begin{abstract}
Resumen: Este trabajo explora las particularidades de la diversidad en el marco del turismo y las singularidades del caso argentino.

El turismo se materializa en la relación entre individuos y los sistemas socionaturales que visita temporalmente. En esta relación, el turista se vincula con los diversos aspectos del destino turístico: naturales, sociales, artificiales, culturales, políticos, económicos.

El creciente posicionamiento argentino como destino turístico implica el arribo de nuevos grupos significativos: realidad inédita que supone renovadas reflexiones sobre multiculturalidad.

Asimismo, los visitantes se vinculan con los habitantes del destino en general y, en forma directa, con las personas que trabajan en este sector, roles que implican una inclusión social determinada.

Además, la preeminencia clásica de los atractivos turísticos tradicionales (naturales y culturales tangibles, generalmente monumentales) está dejando espacio a otros atractivos y actividades, característicamente culturales e intangibles: propuestas en las que el turista observador clásico cede lugar al turista activo moderno. El pueblo argentino, portador de esa cultura y parte del atractivo, es presentado con diversos niveles de exposición en la comunicación turística oficial.
\end{abstract}

Palabras claves: destino turístico - inclusión social - multiculturalidad.

[Resúmenes en inglés y portugués y currículums en la página 83]

\title{
Introducción
}

El turismo se materializa en la relación entre individuos y los sistemas socionaturales que visita temporalmente. En esta relación, el turista se vincula con los diversos aspectos del destino turístico: naturales, sociales, artificiales, culturales, políticos, económicos, a la vez que la comunidad receptora toma contacto con el turista y, a través de él, con los diferentes aspectos de su sistema de origen. Se trata de un fenómeno social característicamente multicultural que reúne a personas de distintas esferas de significación.

En la Argentina, el creciente posicionamiento como destino turístico, reforzado con el fin de la convertibilidad, implica el arribo de grupos significativos de nuevos países emisores y la llegada masiva de turistas latinoamericanos. Esta realidad inédita supone renovadas reflexiones en el contexto de la diversidad. Asimismo, los motorizadores del fenómeno, los visitantes, se vinculan con los habitantes del destino en general y con residentes que participan directamente del turismo, personas que trabajan en este sector desempeñando diversos roles: toma e implementación de decisiones públicas, prestación de servicios privados, producción y transmisión de conocimientos. El abigarrado y dinámico ámbito de la intermediación turística implica una participación social con características determinadas. 
Por otra parte, la materia prima del turismo está conformada por atractivos y actividades turísticas. La preeminencia clásica de los atractivos tradicionales (naturales y culturales tangibles, generalmente monumentales) está dejando espacio a otros atractivos y actividades, característicamente culturales e intangibles; se trata de propuestas en las que el turista observador de antes cede lugar al turista activo moderno. En todo caso, los portadores y productores de esa cultura, el pueblo argentino, es presentado con diversos niveles de inclusión en la comunicación turística oficial.

En suma, se pretende describir las aristas de la diversidad en los tres ámbitos sociales específicos del turismo.

\section{El sistema turístico}

El hombre, en tanto ser dotado de movilidad, desde sus primeros días hace uso de esta facultad para satisfacer diversas necesidades: alimento y abrigo, motivos reproductivos y de dominación, curiosidad y salud, seguridad e intercambio comercial, etc. El cazador-reproductor nómada deja lugar al agro-alfarero sedentario, que continua con la práctica de los traslados pero ahora con regreso a su hábitat. Algunos de aquellos motivos desaparecen con el tiempo, pero la mayoría sobreviven, unos tantos se transforman y aún surgen otros nuevos más sofisticados en respuesta a los requerimientos de las sucesivas generaciones. Diversos eventos tecnológicos y sus consecuencias sociales y económicas acontecen entre la Revolución Industrial y las Guerras Mundiales y provocan que cada vez más personas se desplacen en forma transitoria. En efecto, la modernización de los medios de transporte y comunicación, la aparición de la clase media y la extensión de las vacaciones pagas, entre muchos otros factores, devienen en la masificación de los viajes durante el siglo pasado. El flamante fenómeno entonces toma el nombre de Turismo y se formaliza: se crean administraciones públicas ad hoc y florecen empresas especializadas en todo el mundo, las comunidades anfitrionas se capacitan y comienzan a investigar causas y efectos; la existencia del Turismo entre nosotros, en suma, se naturaliza.

La dinámica del fenómeno incluye numerosos entes, actores, elementos que se vinculan entre sí e intercambian información, bienes, capital, valores: el foráneo se relaciona con la comunidad local, el gobierno con los prestadores, el medio natural con el medio construido, etc. Se trata de una red profusa de relaciones cuya compresión puede ser despejada desde un enfoque sistémico, esto es desde la concepción del conjunto de elementos vinculados que conforman la realidad del fenómeno (Navarro, 2007: 48-52)

Para ello, se parte de la presunción de que el acontecimiento del fenómeno turístico consiste en la relación que se establece entre visitantes y destino. Efectivamente, el turismo consiste en un fenómeno social: "fenómeno" porque se trata de una manifestación perceptible por el hombre; "social" porque es protagonizado por el hombre, en contraposición con los fenómenos naturales. Es decir que el turismo es objeto de estudio de las ciencias sociales, a diferencia de los fenómenos de la naturaleza que son explicados por las ciencias naturales o exactas (Física, Geología, Informática, Biología, etc.). La fragmentación que las ciencias sociales sufrieron en manos de la Modernidad dio lugar a diversas ramificaciones (Antropología, Sociología, Ciencia Política, Economía, etc.) que permiten también hablar de Ciencias del Turismo o Turismología o bien preferir la posición genérica, dada la alta transversalidad del turismo y la inevitable tendencia actual de integrar las diversas ramas de las ciencias sociales. Por fin, la referencia a la condición de "fenómeno social" es inclusiva de: fenómeno económico, actividad (económica), industria, servicio, negocio, desplazamiento, práctica (social o 
cultural), derecho (o su ejercicio), etc. Por otra parte, se indicó que el fenómeno ocurre cuando los dos actores principales, visitante y destino, toman contacto; esto incluye las relaciones y procesos que ambas partes experimentan antes del viaje, con el traslado, durante la estancia y los efectos posteriores al viaje, tanto sobre el Subsistema Origen como sobre el de Destino. Asimismo, la referencia a "visitantes" y "destino" tienen alta capacidad descriptiva y evitan connotaciones sesgadas (esto ocurre con los términos: demanda y oferta, subsistemas generador y productor).

\section{Subsistema de Destino}

El ejercicio de simplificar la realidad en sistemas sirve para describirla, explicarla o interpretarla, predecirla e intervenirla. El enfoque sistémico permite desagregar sistemas en subsistemas y éstos en nuevos subsistemas hasta la identificación de elementos de base, en un ejercicio intelectual que se extenderá según el grado de análisis pretendido. En esta ocasión, sólo se desarrollan los seis subsistemas (sus elementos constitutivos y componentes turísticos) del Subsistema de Destino: Medio Natural, Artificial, Cultural, Social, Económico y Político.

La realidad que conforma el universo viene dada (subsistema natural) o ha sido construida por el hombre (demás subsistemas), puede ser tangible (subsistema natural y adaptado) o intangible (demás subsistemas).

1. Subsistema Natural: el medio natural constituye la porción de la realidad tangible dada, es decir de existencia independiente y anterior al hombre. A diferencia de los demás subsistemas, la naturaleza es la protagonista del subsistema y el hombre es un elemento biológico más y su observador: con la intervención humana, los elementos naturales dejarían de serlo y se transformarían en elementos adaptados. La eventual imposibilidad de modificar algunos fenómenos del mundo natural deja la alternativa de preverlos o adecuarse a ellos: este es el tipo de relaciones que conviene identificar al momento de pretender imprimir cambios sobre el sistema. Forman parte de este subsistema las diversas manifestaciones del aire, el agua y la tierra, tanto como la flora y la fauna. El ambiente natural da lugar material al acontecimiento de los fenómenos sociales, provee al turismo de escenario y bienes para aprovechar o transformar.

Ahora bien, no todo el entorno natural está involucrado en el acontecimiento del fenómeno turístico, sino sólo determinados espacios, paisajes y elementos (subsistema natural del turismo). Asimismo, en los seis subsistemas hay elementos o recursos que, dada su capacidad de satisfacer las necesidades que motivaron el viaje, se transforman en atractivos turísticos.

2. Subsistema Artificial: el medio artificial constituye la porción de la realidad tangible construida por el hombre, es decir la transformación cultural del medio natural. El ambiente construido da lugar material al acontecimiento de los fenómenos sociales, provee al turismo de escenario o soporte físico y bienes transformados. Forman parte de este subsistema tanto los espacios adaptados como los artefactos, la infraestuctura y las estructuras.

Para resolver diversas necesidades (funcionales, estéticas, fisiológicas, espirituales, intelectuales, afectivas), el ingenio del hombre produce artefactos y estructuras cuyas funciones específicas dependen de las actividades que facilitan o alojan. Los primeros son bienes muebles producto de la técnica (ej.: computadora, herramienta, ropa) y las segundas son bienes inmuebles producto de la arquitectura (ej.: casa, edificio, plaza); estas últimas también pueden ser referidas como equipamiento e instalaciones (Boullón, 1985: 40-42). Por su parte, la infraestructura son los canales y sus redes 
que albergan flujos de elementos naturales, artificiales (sean tangibles o intangibles) y personas (ej.: acueducto, ruta, cableado); la infraestructura articula estructuras y espacios. De la misma forma, los espacios adaptados son las porciones de la superficie terrestre con modificaciones antrópicas que reúnen estructuras e infraestructura (ej.: ciudad, campo, parque industrial); éstos están constituidos por zonas, áreas, centros, complejos, núcleos, conjuntos, barrios, sectores.

Claro que no todo el entorno artificial está involucrado en el acontecimiento del fenómeno turístico, sino sólo determinados artefactos, estructuras, flujos y espacios (subsistema artificial del turismo). Como en el subsistema anterior, también hay atractivos turísticos artificiales.

3. Subsistema Cultural: el medio cultural constituye la porción de la realidad intangible construida por el hombre en forma colectiva y a lo largo del tiempo. Se trata de todos los elementos cuya existencia dependen del hombre y tienen base en él, por lo que los elementos del subsistema anterior y de los restantes serían desagregaciones de éste, desde una perspectiva conceptualmente rigurosa. El marco cultural provee al turismo de los fundamentos del fenómeno (causalidades e intencionalidades). Forman parte de este subsistema numerosos productos resultantes de todo aquello que la sociedad es (identidad) o parece (imágenes); lo que quiere (valores) y espera (expectativas) o rechaza (negaciones) y aún quita importancia (indiferencias); aquello que la sociedad hace (prácticas) y la forma en que lo hace (procesos), tanto como lo que puede (capacidades) y limita (restricciones); se incluyen las producciones intangibles (conocimientos); lo que se dice (juicios) y lo que se censura (tabúes); tanto aquello que la sociedad cree (ideologías) como lo que descree (dudas); aquello que cambia (evoluciones) y aquello que continúa (permanencias).

Ahora bien, no todo el entorno cultural está involucrado en el acontecimiento del fenómeno turístico, sino sólo determinadas construcciones (subsistema cultural del turismo). Como en cada subsistema, también hay atractivos turísticos culturales.

4. Subsistema Social: el medio social constituye la porción de la realidad intangible construida por el hombre en forma colectiva y en el presente. Se trata de elementos de existencia dependiente del hombre y con base en él. El marco social provee al turismo de los actores del fenómeno. Forman parte de este subsistema numerosos grupos (formales e informales) de la sociedad civil y aún individuos en función de su rol: organismos u organizaciones, entidades o instituciones, asociaciones o sociedades, gremios y sindicatos, cooperativas y mutuales, profesionales e idóneos, docentes e investigadores, institutos y centros, asociaciones vecinales y barriales, clusters y redes, universidades, cámaras, corporaciones, clubes. Claro que no todo el entorno social está involucrado en el acontecimiento del fenómeno turístico, sino sólo determinados personajes, colectivos e instituciones (subsistema social del turismo). Una vez más, en este subsistema se encuentran atractivos turísticos sociales.

5. Subsistema Económico: el medio económico constituye la porción de la realidad intangible construida por el hombre a partir de sus transacciones mercantiles en la esfera privada. Se trata de elementos de existencia dependientes del hombre y con base en él. El marco económico provee al turismo de los elementos de intercambio comercial. Forman parte de este subsistema numerosos actores de la sociedad económica y elementos como bienes, servicios, paquetes, productos.

Ahora bien, no todo el entorno económico está involucrado en el acontecimiento del fenómeno turístico, sino sólo determinados elementos (subsistema económico del turismo): así, se incluyen las prestaciones turísticas básicas (alojamiento, gastronomía y transporte), complementarias (esparcimiento, 
comercialización, seguridad) y específicas; todo paquete turístico puesto en el mercado; los macroproductos turísticos característicos de un destino (turismo de sol y playa, científico, activo, cultural, deportes, interés especial, salud); los colectivos propios del turismo comercial (agentes y operadores, guías y profesionales, hoteleros y gastronómicos); y las instituciones características de la actividad privada. Como en los demás subsistemas, también hay atractivos turísticos económicos (prácticas y procesos, estructuras y sistemas, grupos e instituciones), aunque técnicamente tienen base sociocultural.

6. Subsistema Político: el medio político constituye la porción de la realidad intangible construida por el hombre a partir de sus relaciones de poder en la esfera (pública). Se trata de elementos de existencia dependiente del hombre y con base en él. El marco político provee al turismo de decisiones públicas obligatorias. Forman parte de este subsistema numerosos actores de la sociedad política y elementos como demandas, planes, acciones, normativa.

Claro que no todo el entorno político está involucrado en el acontecimiento del fenómeno turístico, sino sólo determinados elementos (subsistema político del turismo). Como en los demás subsistemas, también hay atractivos turísticos políticos (prácticas y procesos, estructuras y sistemas, grupos e instituciones), aunque técnicamente tienen base sociocultural.

\section{Subsistema de origen y visitantes}

Los Visitantes provienen del componente social del Subsistema de Origen y, en tal ámbito, se vinculan con sus aspectos naturales, artificiales, culturales, económicos, políticos y con sus pares, es decir con aspectos sociales. Esto significa que, aunque el Subsistema de Destino toma contacto con los Visitantes, a través de éstos se vincula con todo el Subsistema de Origen: los Visitantes constituyen personas configuradas por las características de sus ámbitos de Origen y las relaciones que establezcan con el Destino estarán definidas por tales características. Es decir, desde una perspectiva social, los Visitantes son un grupo informal particular; desde un punto de vista económico, constituyen la demanda; desde la óptica política, los Visitantes son "ciudadanos temporarios"; desde un enfoque cultural, constituyen agentes exógenos portadores de construcciones materiales e inmateriales.

A partir de este "mapa del sitio" y en función de observaciones sobre diversidad, es útil reconocer que los grupos humanos involucrados son tres: los turistas, particularmente internacionales (subsistema social del Subsistema de Origen); los residentes que participan del mundo del turismo como intermediarios, no solamente en actividades comerciales (grupos e instituciones turísticas del subsistema social del Destino); y aquéllos que forman parte del fenómeno como "atractivos turísticos sociales": personajes o comunidades que, en virtud de características de interés, motivan el traslado de visitantes para observar o participar en actividades con ellos. En suma, la diversidad en el turismo es observable, al menos, en estos tres lugares. A continuación, se procura caracterizar la inclusión o exclusión social en la demanda turística internacional, en la intermediación turística (particularmente en el empleo turístico) y en la oferta turística (especialmente en la oferta oficial comunicada).

\section{La demanda turística internacional}

Con la finalización del plan de convertibilidad financiera, la Argentina se convirtió en un destino competitivo que, desde 2003, experimentó un crecimiento en los arribos turísticos en general, a la vez que se diversificaron los países emisores. Resulta entonces un mosaico profuso de visitantes de diversos puntos del globo y una marcada presencia de turistas latinoamericanos. 
Esta sección afina lecturas realizadas con anterioridad (García y Seitz, 2005) y revisa datos producidos en la Secretaría de Turismo de la Nación (SecTur, 2004 y SecTur, 2005b) y en el Instituto Nacional de Estadísticas y Censos de la Nación (INDEC, 2005a e INDEC, 2005b), a la vez que encuentra contexto internacional en registros de la Organización Mundial del Turismo (OMT, 2005) y del Banco Mundial (WB, 2004).

\section{América Latina}

Las llegadas de la región sudamericana, para comenzar, son las siguientes:

\begin{tabular}{|c|c|c|c|c|c|c|c|}
\hline \multirow[t]{2}{*}{ Países (1) } & \multicolumn{3}{|c|}{ Llegadas a Argentina 2005 (2) } & \multicolumn{2}{|c|}{$\begin{array}{l}\text { Gasto de turismo internacional } \\
\text { en Argentina } 2004\end{array}$} & \multicolumn{2}{|c|}{$\begin{array}{l}\text { Gasto de turismo internacional } \\
2004 \text { (3) }\end{array}$} \\
\hline & Orden & Cant. & Variac. & Orden & Porcentaje & Orden & Cantidad \\
\hline Brasil & $1^{\circ}$ & 28.896 & $26.4 \%$ & $2^{\circ}$ & 9.06 & $2^{\circ}$ & 2.871 \\
\hline Chile & $2^{\circ}$ & 21.319 & $20.1 \%$ & $1^{\circ}$ & 17.06 & $4^{\circ}$ & 892 \\
\hline Perú & $8^{\circ}$ & 5.766 & $-3.4 \%$ & & & $6^{\circ}$ & 620 \\
\hline Colombia & $10^{\circ}$ & 5.305 & $21 \%$ & & & $3^{\circ}$ & 1.290 \\
\hline Venezuela & $12^{\circ}$ & 2.859 & $30 \%$ & & & & \\
\hline Ecuador & $13^{\circ}$ & 2.629 & $22.9 \%$ & & & $8^{\circ}$ & 391 \\
\hline Bolivia & $14^{\circ}$ & 2.346 & $15.6 \%$ & $5^{\circ}$ & 1.36 & & \\
\hline Uruguay & $15^{\circ}$ & 2.260 & $14.8 \%$ & $4^{\circ}$ & 6.17 & & \\
\hline Paraguay & $18^{\circ}$ & 19.38 & $58.6 \%$ & $3^{\circ}$ & 9.01 & & \\
\hline
\end{tabular}

(1) Se presentan sólo los datos de cantidad y variación de los primeros 20 países sudamericanos en cada lista mundial.

(2) Registro del Aeropuerto Internacional de Ezeiza - Octubre de 2005. Orden en el ranking mundial y variación respecto de octubre de 2004.

(3) Orden dentro del grupo sudamericanos y cantidad en millones de dólares.

En su conjunto, las visitas sudamericanas (México incluido) a la Argentina entre enero y septiembre de 2005 representaron un $48.68 \%$ del total del turismo receptivo internacional, incremento considerable en comparación con el promedio 1999-2003: 29.86\%. Asimismo, el gasto de tales visitas en 2004 representó el 52.78\% del total por parte de turistas extranjeros; la primer mitad del 2005 gastaron $28.58 \%$ más que la primer mitad del año anterior.

Brasil, Chile y Perú constituyen los tres países sudamericanos que más viajeros aportan a la Argentina hacia el 2005. Obsérvese que: 1 . Además de la cantidad absoluta, la evolución del turismo ingresado desde Brasil aumentó cinco puntos sobre el promedio en un año; 2. Aunque Perú está entre los primeros diez mercados de la Argentina, su involución es notable: 23 puntos por debajo del promedio; 3. Ecuador, Venezuela y Paraguay incrementaron sus visitas a la Argentina en un año en proporciones crecientes según el orden expuesto. Por otra parte, ninguno de los países sudamericanos se encuentra entre los 20 principales emisores de turismo en el mundo, motivo por el que no se presenta la información correspondiente (Argentina es el primer país sudamericano de la lista, en el puesto 39). 
Los tres países sudamericanos que más gastaron en turismo en la Argentina durante el año 2004 son Chile, Brasil y Paraguay; al respecto cabe indicar que: 1. El orden Brasil-Chile en cantidad de visitas se invierte al momento de considerar sus gastos; 2. Aunque Perú se ubica entre los mercados principales por la cantidad de visitantes, el gasto realizado no alcanza para posicionarlo entre los cinco países que más beneficios económicos reportan a la Argentina, sus repercusiones turísticas entonces se inscriben más bien en ámbitos sociales y culturales; 3. Inversamente, Paraguay se ubica al final de la lista de los 20 países que más visitan la Argentina, pero se posiciona tercero entre los que más gastan, casi a la altura de Brasil.

Finalmente, se señala que los tres países sudamericanos que más gastaron en turismo internacional en el mundo (excluyendo a la Argentina) son Brasil, Colombia y Chile. Colombia entonces constituye un mercado con cierta potencialidad aún no aprovechada ya que, aunque está entre los 10 países que más visitan la Argentina, no se encuentra entre los que más gastan en ella.

México se cuenta en la lista de los principales 20 países emisores de turistas al mundo (puesto 14) con 13.653.676 viajeros en 2004; estas cifras denotan un crecimiento del $23.24 \%$ desde 2000 : casi 3.5 veces sobre el promedio. Detrás de los otros países del norte y considerando el grupo americano, México es el tercero que más gastó en turismo internacional en 2004: 6.959 millones de dólares en 2004. Para Argentina representa un mercado de interés dado que la cantidad de viajeros desde México posicionan a ese país en el sexto lugar entre los emisores al nuestro, con lo que la variación de visitas mexicanas creció en un 28.1\%: siete puntos sobre el promedio. México es un mercado legítimamente argentino dado que, aunque en el plano mundial se ubica después que Canadá en salidas y gastos por turismo internacional, en el caso argentino el orden se invierte

\section{Canadá y los Estados Unidos}

Canadá es uno de los principales países emisores de turistas en el mundo, lista en la que ocupó el puesto 11 en 2004, si bien las salidas de turismo internacional desde ese país decrecieron en $-4.63 \%$ en los primeros cinco años del siglo. Entre los países americanos, Canadá es el segundo que más gastó en turismo internacional en 2004 (16.017 millones de dólares). Para Argentina, se trata de un mercado efectivo importante y en crecimiento: ocupó el $17^{\circ}$ lugar entre los que más visitaron el país en octubre del 2005; con lo que manifiesta un crecimiento del 27.1\% respecto de octubre del 2004 (seis puntos sobre el promedio).

Aunque los Estados Unidos en 2004 se mantenía en el tercer lugar como país emisor de turistas en el mundo (60.271.981), en el primer quinquenio del siglo, decreció por debajo de cero $(-1.02 \%)$. En el marco del grupo de las "Américas" de la OMT, los Estados Unidos son el país que más gastó en turismo en el exterior: 65.635 millones de dólares en 2004. En octubre de este año, los arribos a la Argentina desde ese país lo posicionaron como la cuarta demanda (26.3\%), con un incremento creciente respecto del mismo mes del año anterior de cinco puntos sobre el promedio. 


\section{La Unión Europea}

Podemos resumir, siguiendo las mismas fuentes de referencia anteriormente indicadas, cómo sigue el movimiento económico generado por el turismo de la Unión Europea:

\begin{tabular}{|c|c|c|c|c|c|c|c|c|}
\hline \multirow[t]{2}{*}{ Países (1) } & \multicolumn{3}{|c|}{ Llegadas a Argentina 2005 (2) } & \multicolumn{3}{|c|}{$\begin{array}{l}\text { Salidas de turismo internacional } \\
2004 \text { (3) }\end{array}$} & \multicolumn{2}{|c|}{$\begin{array}{l}\text { Gasto de turismo } \\
\text { internacional } 2004(4)\end{array}$} \\
\hline & Orden & Cant. & Variac. & Orden & Cant. & Variac. & Orden & Cant. \\
\hline España & $3^{\circ}$ & 19.642 & $35.9 \%$ & $34^{\circ}$ & & & $8^{\circ}$ & 12.156 \\
\hline Francia & $5^{\circ}$ & 8.052 & $4.9 \%$ & $9^{\circ}$ & & & $3^{\circ}$ & 28.636 \\
\hline Italia & $7^{\circ}$ & 6.146 & $7.3 \%$ & $6^{\circ}$ & 26.616 .790 & $21.02 \%$ & $4^{\circ}$ & 20.544 \\
\hline Alemania & $9^{\circ}$ & 5.353 & $7.2 \%$ & $1^{\circ}$ & 84.572 .381 & $13.67 \%$ & $1^{\circ}$ & 72.271 \\
\hline Gran Bretaña & $11^{\circ}$ & 4.283 & $10.4 \%$ & $2^{\circ}$ & 66.065 .790 & $16.24 \%$ & $2^{\circ}$ & 55.930 \\
\hline Israel & $16^{\circ}$ & 2.191 & $126.1 \%$ & $32^{\circ}$ & & & $18^{\circ}$ & 2.796 \\
\hline Suiza & $20^{\circ}$ & 1.713 & $47.5 \%$ & $17^{\circ}$ & 11.309 .800 & -8.6 & $11^{\circ}$ & 8.797 \\
\hline Polonia & & & & $4^{\circ}$ & 47.635 .400 & -15.96 & $14^{\circ}$ & 3.906 \\
\hline República Checa & & & & $7^{\circ}$ & 26.124 .800 & -30.29 & $21^{\circ}$ & \\
\hline Federación Rusa & & & & $8^{\circ}$ & 25.873 .400 & $40.84 \%$ & $6^{\circ}$ & 15.730 \\
\hline Holanda & & & & $12^{\circ}$ & 17.104 .600 & $23.09 \%$ & $5^{\circ}$ & 18.539 \\
\hline Hungría & & & & $15^{\circ}$ & 11.841 .505 & $7.02 \%$ & $17^{\circ}$ & 2.864 \\
\hline Suecia & & & & $16^{\circ}$ & 11.726 .800 & $12.76 \%$ & $10^{\circ}$ & 10.123 \\
\hline Ucrania & & & & $18^{\circ}$ & 9.216 .867 & $6.50 \%$ & $22^{\circ}$ & \\
\hline Finlandia & & & & $20^{\circ}$ & 6.582 .100 & $11.3 \%$ & & \\
\hline
\end{tabular}

(1) Se presentan sólo los datos de cantidad y variación de los primeros 20 países europeos en cada lista mundial.

(2) Registro del Aeropuerto Internacional de Ezeiza - Octubre de 2005. Orden en el ranking mundial y variación respecto de octubre de 2004.

(3) Orden en el ranking mundial y variación 2000-2004.

(4) Orden dentro del grupo europeo y cantidad en millones de dólares.

En su conjunto, las visitas europeas a la Argentina entre enero y septiembre de 2005 representaron un $25.86 \%$ del total del turismo receptivo internacional, incremento considerable en comparación con el promedio 1999-2003: 12.8\%. Asimismo, el gasto de tales visitas en 2004 representó el 29\% del total por parte de turistas extranjeros; en la primera mitad del 2005 gastaron un 30\% más que igual período del año anterior.

Los cinco países europeos que más viajeros aportan a la Argentina hacia fines del 2005 son España, Francia, Italia, Alemania y Gran Bretaña. Más allá de los datos absolutos, interesa observar que: 1. España es un mercado legítimamente argentino dado que no es un país que se encuentre entre los principales emisores de turismo en el mundo y presenta un destacable crecimiento respecto de año anterior (2004) en viajes a nuestro país (más de 1.5 vez sobre del promedio); 2. Aunque Suiza está 
al final de la lista de los 20 países que más visitan la Argentina, constituye un mercado en amplia expansión para el país respecto del año anterior, el 2004 (más de dos veces sobre el promedio); 3. Israel ocupa el lugar 16 entre los que más viajeros emiten a la Argentina, no está entre los 20 países que más viajan en el mundo ni entre los cinco europeos que más gastan, pero el incremento de visitas desde ese país creció significativamente en un año (casi seis veces sobre el promedio), por lo que su importancia es más social y cultural que económica.

Los cinco países europeos registrados entre los principales emisores de viajeros en el mundo en 2004 son Alemania, Gran Bretaña, Polonia, Italia y la República Checa; en relación con la Argentina cabe indicar: 1. Polonia y la República Checa son aún mercado potenciales para la Argentina, el primero con mayor capacidad de gasto que el segundo y ambos en discreto decrecimiento mundial en el primer quinquenio del siglo; 2. La Federación Rusa, también mercado potencial para la Argentina, es un importante emisor de turistas en el mundo, con alta capacidad de gasto y desde 2000 creció significativamente (más de seis veces sobre el promedio).

Finalmente, se señala que los cinco países europeos que más gastaron en turismo internacional en 2004 son Alemania, Gran Bretaña, Francia, Italia y Holanda; el último de ellos no se encuentra aún entre los 20 que más visitan la Argentina.

\section{Asia Oriental}

China representa un destacadísimo mercado prioritario hacia el cual dirigir esfuerzos promocionales de turismo. Aunque en 2005 no se encontraba entre los veinte países que más visitaban la Argentina, está posicionado en el décimo lugar entre los principales países emisores de turismo en el mundo, con 19.072.400 viajeros registrados en 2004; esto es un crecimiento del 321.96\% desde 1995: cinco veces y medio el promedio mundial. Asimismo, es el segundo país asiático entre los que más gastaron en turismo internacional (13.258 millones de dólares).

Japón, por su parte, ocupó el puesto 13 entre los principales países emisores de turistas hacia diversos destinos mundiales, con 16.753.486 viajeros desplazados desde ese país en 2004; el incremento de viajes realizados desde Japón en los últimos entre 1995-2005, sin embargo, estuvo más de seis veces por debajo del promedio mundial (9.51\%). Asimismo, el gasto de sus turistas en el mundo alcanza las cifras más elevadas entre los del grupo asiático: 38.129 millones de dólares en 2004.

Por otra parte, 8.083.829 viajeros salieron de Corea en 2004, con lo que este país se ubica en la posición 19 entre los principales emisores de turistas al mundo y acusa un crecimiento del $111.67 \%$ en diez años: casi el doble del promedio mundial. Se destaca también el gasto efectuados por los viajeros originarios de Corea en el mundo, 9.499 millones de dólares en 2004, con lo que gana el tercer lugar en el grupo asiático.

Finalmente, se observa el caso de Malasia y Taiwán. El primero de ellos fue en 2004 el quinto país del ranking mundial de emisores de turismo internacional; en este sentido, creció un 100.86\% en diez años, aunque su capacidad de gasto en turismo internacional lo posterga al décimo lugar del grupo asiático. Contrariamente, Taiwán no se destaca por las cifras de turistas emitidos, pero es el quinto país asiático que más gastó en turismo internacional en 2004.

\section{India}

La cantidad de viajeros desde ese país hacia diversos destinos del globo es destacable: en 2004, se registraron 4.365 .067 salidas, cifra que representa un crecimiento del 42.84\% en la década 1995-2005 y lo posiciona en el puesto 29 de los principales países emisores de turismo en el mundo. El cálculo del 
gasto en el exterior realizado por viajeros procedentes de la India asciende a 5.072 millones de dólares, con lo que se ubica séptimo en el ranking del grupo "Asia y el Pacífico" de la OMT. Los arribos a la Argentina desde la India no se encuentran entre los primeros 20 del ranking.

\section{Sudáfrica}

En la década de 1995-2005, el número de turistas hacia el mundo originarios de Sudáfrica creció en un 19.36\%; con 3.007.800 salidas registradas en 2004, este país ocupa el puesto 40 entre los países emisores de turismo. En el marco del grupo "África" de la OMT, Sudáfrica es el segundo país que más gastó en turismo en el exterior: 2.668 millones de dólares en 2004, detrás de Arabia Saudita. Al igual que la India, las llegadas a la Argentina desde este país no están en el ránking de los primeros 20.

\section{Australia}

En octubre del 2005, se cuenta entre los 20 países que más visitan la Argentina (puesto 19) y acusa un crecimiento del $23.7 \%$ respecto del mismo mes en el año anterior (casi cuatro puntos por encima de la media). Asimismo, ocupa el puesto 33 entre los principales países emisores de turismo con 3.687.800 viajeros contabilizados desde Australia al mundo en 2004; se trata de un mercado en franca expansión que creció un $69.94 \%$ en diez años, es decir más de once puntos por encima del promedio mundial. De la misma forma, se ubica en el cuarto lugar entre los países con mayores egresos por turismo del grupo "Asia y el Pacífico" con 9.407 millones de dólares en 2004.

\section{El empleo turístico}

Respecto al subsistema social del turismo, es decir los residentes del destino turístico vinculados directamente en el fenómeno del turismo, sólo es posible trabajar con datos de aquéllos cuya relación es laboral. En efecto, la preocupación de la Secretaría de Turismo de la Nación por la cuantificación y descripción de la categoría conceptual "empleo turístico" permite caracterizar a los trabajadores del sector y observar el estado de diversidad en términos de género, edad, nivel educativo y distribución geográfica (Oliva y Schejter, 2007).

\section{Género}

Del total de los empleados en las ramas características del turismo, la proporción de hombres $(57,8 \%)$ es mayor que la de mujeres $(42,2 \%)$. En todo caso, la inserción laboral de las mujeres es mucho mayor que décadas atrás debido al proceso de modernización social. Al mismo tiempo, subsisten factores culturales que postergan a las mujeres a ciertos puestos de trabajo, estereotipos de género que las categorizan como aptas o no para el desempeño de ciertos puestos. En ciertas ramas, el predominio de la mano de obra masculina es mayor. Así, casi la totalidad de los empleados en transporte ferroviario $(74,2 \%)$ y el transporte automotor $(92,8 \%)$ son hombres cuando no hay impedimentos verdaderos para que las mujeres cumplan esas funciones. En otras ramas la distribución es más homogénea, es el caso de las empresas de viajes, donde la distribución se acerca a la distribución total de empleados por género. Asimismo, en servicios de alojamiento, se invierte la situación y se observa un tenue predominio de empleo femenino $(54,7 \%)$. 


\section{Edad}

Los grupos etáreos de menor edad se concentran en los servicios gastronómicos: el 11,3\% de los ocupados tienen menos de 21 años. Acaso las responsabilidades familiares sean menos entre los jóvenes, situación que favorece la movilidad y la posibilidad de trabajar en horarios nocturnos. Además, los jóvenes se adaptan con mayor facilidad a las condiciones de menor estabilidad y de fuerte estacionalidad asociadas a los empleos turísticos. Por el contrario, en transporte aéreo y por vía acuática se advierte una alta concentración de ocupados de 21 a 40 años.

\section{Nivel educativo}

El 18,5\% de los trabajadores captados por la Encuesta Permanente de Hogares tiene estudios universitarios completos, un $21,7 \%$ tiene secundaria completa y el 21,5\% primaria completa. Los promedios aumentan entre los empleados de transporte aéreo: la proporción de trabajadores con educación universitaria o superior es del 28,1\%. Lo propio ocurre en servicios culturales y museos: 30,1\%. Por el contrario, en transporte automotor y en servicios de alojamiento se destacan los trabajadores con primario completo.

\section{Distribución geográfica}

La estacionalidad son muy marcadas en muchas regiones argentinas. Con base en la Encuesta de Ocupación Hotelera, se pueden estimar las variaciones estacionales de los puestos de trabajo en la hotelería. En el 2005, los puestos de trabajo en hoteles por mes mostraban una caída fuera de la temporada en varias regiones, principalmente en Buenos Aires, vinculada al turismo de "sol y playa" en la Costa Atlántica, y en la Patagonia, donde la estacionalidad de los ciclos turísticos es agravada por los factores climáticos. Por el contrario, en la Patagonia se advirtió una fuerte creación de empleos hoteleros en el 2005: 6.723 empleados. La Ciudad de Buenos Aires, en ese mismo año, dio trabajo en hoteles a 14.857 personas.

\section{La oferta turística}

Los destinos y productos turísticos históricamente han encontrado en el material impreso de distribución masiva y gratuita su principal herramienta de información, incluso ante el advenimiento de los medios audiovisuales (radio, televisión, cine, video, disco compacto) y virtuales (sitio web). En la Argentina, la tradición se ha extendido ampliamente y, en el plano nacional, el ente nacional de turismo ha editado innumerables folletos y panfletos, pósters y revistas a lo largo de su trayectoria. Las tres publicaciones analizadas (folleto, mapa y revista) constituyen el principal material de promoción turística nacional escrito, impreso y distribuido a públicos foráneos (Navarro, 2008). Se focaliza en el quinquenio 2000-2007 dada la uniforme continuidad en la concepción promocional: si bien el material se diagrama durante la última gestión radical (algunos gráficos, fotos y textos son incluso reciclados de publicaciones anteriores), se continúa utilizando en las posteriores gestiones justicialistas. Las mismas publicaciones atraviesan cuatro períodos de gobierno (sin contar las presidencias efímeras entre de la Rua y Duhalde) pero la sostenibilidad de enfoque termina más allá del material integral y regional: la selección y priorización de los productos turísticos a promocionar cambia constantemente.

En 2005 se presenta el Plan Federal Estratégico de Turismo Sustentable “Turismo 2016” (Turismo, 2005) que propone diversos productos y subproductos con diferencias respecto de la selección anterior: aunque los cambios son importantes en el documento, no se reflejan en la práctica y se sigue 
utilizando la misma folletería. También es posible distinguir perspectivas promocionales diferentes en los períodos de gobierno anteriores al abordado en este trabajo.

La proyección exterior de la imagen turística, cristalizada en la distribución del material a extranjeros ocurre tanto en el plano internacional como doméstico. Dentro de las fronteras del país, principalmente a través de la entrega en centros de información turística del gobierno nacional y, en proporción menor, desde oficinas provinciales y municipales de turismo. En otros países, la Secretaría de Turismo participa en ferias especializadas y otros eventos. Asimismo, el área de turismo de Cancillería recibe el material y lo redistribuye entre las representaciones argentinas en el exterior.

\section{Actores centrales: europeos, decimonónicos, artistas}

Hay un grupo de personas que son enfatizadas con orgullo y romanticismo, introducidas con nombre propio: Bustillo, Pelli, Mora, Guido, Fioravanti, Bigatti, Gaudí, Le Corbusier, Rodin, Botero, Thays (Fangio es nombrado indirectamente a través de su museo). Se trata de artistas (arquitectos y paisajistas, escultores y plásticos) de fines del siglo XIX en adelante y vinculados con Buenos Aires o el Litoral. La mitad de ellos son argentinos; la otra mitad son extranjeros, generalmente europeos, que no residieron aquí.

De la historiografía nacional consolidada, llama la atención la ausencia de San Martín, Sarmiento, Roca al menos. Belgrano aparece una vez, asociado al Monumento a la Bandera. Sin ser nombrados, Urquiza se adivina detrás del Palacio San José y Güemes se filtra en la figura de sus gauchos. El recorte no responde al marketing turístico internacional porque tampoco aparecen los consagrados Perón, Eva, el Che ni los dictadores militares. Es probable que las respuestas tengan relación con la inexistencia de edificaciones sobresalientes vinculadas con los personajes, con la distancia a Buenos Aires de los sitios asociados con ellos, con la vigencia de ideologías políticas o hechos históricos que los involucraron.

Tampoco se recuerdan actores relevantes de las letras, las ciencias, las artes performativas y visuales, el deporte (el país es una cancha propicia para los turistas antes que semillero de personalidades; cabe recordar aquí la mención aislada de Fangio), la religión (aunque la institución católica resulte central). En un sentido más anónimo, los inmigrantes europeos arribados entre fines del siglo XIX y la primera parte del siglo XX son referidos, si no con especial acento, al menos sin descrédito alguno. Las comunidades más citadas son la italiana, española, galesa y andaluza; los judíos y los orientales se hacen visibles como una excepción. Ciertamente, no hay registro de la inmigración proveniente de países limítrofes, árabes ni europeos del este. Asimismo, el dato del idioma en uso en algún caso señala, además del español, el "inglés, francés e italiano" como lenguas extendidas: se fuerza el dominio de tres idiomas probablemente a partir de su origen europeo. Con la misma fuerza, se afirma que el "95\% [de la población] es de raza blanca": la inconsistencia del dato se confunde con su irrelevancia y con el vocabulario discriminatorio. En forma casi excluyente, los inmigrantes son vinculados con Buenos Aires (aunque tienen un museo en el Litoral). Cabe apuntar que, previsible de una sociedad distinguida, la capital no sólo aloja al poder nacional, también la pujanza económica (evidente en su perfil de edificios impresionantes) y la cultura más elegante (cristalizada en sus teatros y museos).

\section{Arquetipos pintorescos: indios, gauchos y hombres del tango}

Está extendida la asociación romanticista del pueblo argentino con algunos de sus arquetipos pretéritos, congelados en el pasado aunque difícilmente formen parte del paisaje actual y caricaturizados en determinados roles y atuendos, necesariamente cargados de música y color. Tales personajes no dejaron de existir sino que sus actividades y/o vestimentas experimentaron cambios con el tiempo 
que la imagen turística actual no siempre recupera.

La idea del progreso localizado en Buenos Aires que se diluye con la distancia se repite en la selección de arquetipos. Estos personajes, a su vez, denotan momentos históricos específicos que, por una parte, grafican los capítulos principales de la historiografía argentina clásica y, por otro lado, también se remontan en el tiempo a medida que se alejan de la capital.

Entonces, los indios pertenecen al Norte (omahuacas, quilmes) y, en menor medida, a la Patagonia y al Litoral. Representan un peldaño inferior de evolución y se manifiestan en pinturas rupestres (Cueva de las Manos) y artesanías, descripciones multicolores y repetidos lugares comunes del pintoresquismo. Su extensiva presentación a través de ruinas (Schincal, Quilmes) hacen del resto material un fetiche: objeto de admiración en su nostálgica belleza ya que, excepto para los entendidos, transmite poco más que decadencia, culturas perimidas y vencidas.

Los gauchos pertenecen a la región central (que alberga el Museo Gauchesco y el de Platería), un poco al Norte y al Litoral (hay también alguno en Cuyo). Son criollos que resultan del mestizaje local con los hijos de la España colonial. Es posible encontrarlos perfectamente ataviados y en ejercicio de sus actividades rurales; también se deducen de sus poblados y viviendas de adobe, de sus fiestas populares e instrumentos musicales. Los "Gauchos de Güemes" son un subgrupo destacado.

Malevos, compadritos, guapos y otros personajes del mundo del tango residen inexorablemente en Buenos Aires y, más europeos que americanos, resultan de la mixtura hispanoamericana con los nuevos inmigrantes del Viejo Mundo. Cabe indicar que el diseño mismo de un producto turístico específico dedicado al tango denota la preferencia por una manifestación específica del arte vernáculo que, acaso justificada desde el mercado internacional, resalta de otras músicas y danzas nativas.

Desde el mismo enfoque romanticista se comprende la categorización de "mito" para la Patagonia: concepción fabulosa y atemporal protagonizada por actores fantásticos y heroicos, como es el caso de los prisioneros y los salesianos sugeridos en sus respectivos museos.

\section{Comunidades negadas: negros e indígenas}

Caricaturizado el aborigen histórico, conviene disimular su descendencia actual: con poco rigor fenomenológico, confundiendo el significado de "mestizaje" y anclado en concepciones de "razas puras", se afirma que menos del $5 \%$ de la población es mestiza y que hay un " $0,5 \%$ de población aborigen pura”. Asimismo, la información sobre lenguas en uso en el país indica sólo la selección oficial (castellano): queda oculto el dato de las lenguas americanas vivas (quechua, guaraní, mapuche) ya que los indígenas son personajes del pasado.

Peor suerte toca a los negros, ayer esclavizados y hoy negados por completo. Situados algún nivel por debajo de los indígenas, no ganan referencias escritas más que en virtud de su eliminación, proceso efectivo del que resultan "esfumados habitantes negros". Tampoco imágenes más que la alusión relativamente vinculante del carnaval que, por cierto, es protagonizado por mujeres que no son negras. Aunque el mestizaje genético y cultural se impone en la realidad, el mensaje turístico prefiere no hacerlos visibles.

\section{Comunidades revalorizados: aborígenes}

En un par de ocasiones se refiere a los indígenas como grupo vigente, continuación de los prehispánicos. Se apunta la posibilidad de "experiencias con descendientes de nuestros pueblos originarios y de otras partes del mundo", con lo que se iguala el antecedente aborigen con el inmigrante (no sólo europeo) y se recurre a un "nosotros" argentino. Asimismo, en la Patagonia, se menciona a las "agrupaciones indígenas de los mapuches" que no son nominadas como "reservas". 


\section{Nuevos actores: modernos, populares y anónimos}

Asimismo, se recuperan diversos actores cotidianos y modernos para representar al país, acaso con la misma veta costumbrista, pero sin recurso a los reiterados arquetipos. De esta forma, pueblan el Norte, el Litoral y Buenos Aires "artistas", “artesanos", "pescadores locales", "vecino-guardián”, “experto en empanadas", feriante de antigüedades, integrantes de murgas. Jugadores de fútbol, actores, bailarines, cantantes de ópera, guardaparques, esquiladores, "orquestas", "arquitectos" y "enólogos" se mezclan entre los productos. Los recursos humanos facilitadores de la experiencia recreativa son también citados: "guías", "instructores", "profesionales" de la salud, "caddies", cocineros.

\section{Balance}

Después de revisar algunos datos sobre la composición de los visitantes temporales al país y sobre la porción de la sociedad argentina que oficia de anfitrión directo, es posible inducir la amplia diversidad de personas que se ponen en contacto en el acontecimiento de éste fenómeno: millones de individuos de diferentes esferas socioculturales que se trasladan en forma voluntaria, que se disponen a aprehender datos del destino, que participan de un intercambio incompatible con la violencia física. En suma, el turismo se trata de una oportunidad que naturalmente se asocia con la idea de multiplicidad cultural y que deliberadamente puede ser aprovechada para comunicar los distintos colores del país. Una comunidad nacional que será unificada antes que homogénea, como viene enseñando el "mito nacional" desde hace más de cien años. Junto con la diversidad natural extendida en la identidad y en la imagen turística, aún es posible desarrollar otras dimensiones de la diversidad: el mestizaje afroindígena-europeo, con ingredientes árabes y orientales; varias regiones con distintos valores y posibilidades, más allá de la capital; sectores y regiones económicas trascendentes de la agricultura pampeana.

Esta oportunidad supone una tarea compleja que incluye la revisión de los recursos socionaturales que son seleccionados como atractivos turísticos, su puesta en valor (conservación-restauración y proyección social) y comunicación, la conformación de paquetes y productos turísticos, su promoción y comercialización.

\section{Referencias Bibliográficas}

Boullón, Roberto. (1985), Planificación del espacio turístico, Editorial Trillas, México (1ra. reimpresión, 1991).

García, Alejandro y Seitz, Mirka. (coord.) (2005). Enfoque de Relaciones Internacionales para la Estrategia Marca Argentina. Buenos Aires: Marca Argentina.

INDEC. (2005). Encuesta de Turismo Internacional, Instituto Nacional de Estadísticas y Censos, Dirección Nacional de Cuentas Internacionales, Buenos Aires.

(2005). Informe de Avance de Turismo Receptivo, Instituto Nacional de Estadísticas y Censos, Dirección Nacional de Cuentas Internacionales, Buenos Aires.

Navarro, Diego. (2008), "La imagen turística argentina”, s.p.

(2007). “Sistema Turístico Mendocino”, en: TurPlan II-Plan de Desarrollo Turístico de Mendoza 2007-2011, Ministerio de Turismo y Cultura, Subsecretaría de Turismo, Mendoza.

Oliva, Miguel y Schejter, Constanza. (2007). El empleo en las ramas características del turismo en Argentina, Secretaría de Turismo, Turismo 2016-Plan Federal Estratégico de Turismo Sustentable, Buenos Aires.

OMT. (2005). WTO World Tourism Barometer. October 2005, Vol. 3, № 3, Organización Mundial del Turismo, Madrid. SecTur. (2005). Turismo 2016-Plan Federal Estratégico de Turismo Sustentable, Secretaría de Turismo y Consejo Federal de Inversiones, Buenos Aires. 
(2005). Turismo Internacional. Aeropuerto Internacional de Ezeiza. Secretaría de Turismo, Dirección de Estudios de Mercados y Estadísticas, Buenos Aires.

(2004). Llegada a las fronteras de turistas extranjeros por país de origen. Total del país. Años 1999-2003, Secretaría de Turismo, Dirección de Estudios de Mercados y Estadísticas, Buenos Aires.

WB. (2004). World Development Indicators, The World Bank.

\begin{abstract}
Summary: This work explores tourism diversity and its singularities in Argentina. Tourism materializes the relation between individuals and the socio-natural systems which they visit temporarily. In the framework of this relationship, the tourist ties with the diverse aspects of the tourist destiny: natural, social, artificial, cultural, political and economic. The increasing Argentine positioning as tourist destiny implies the arrival of new relevant groups: a new reality that supposes renewed reflections on cultural diversity. Also, tourists tied both with the inhabitants of the destiny and with the people who work in this sector implying a certain social inclusion. In addition, the pre-eminence of traditional tourist attractive (tangible) is leaving space to another kind of attractive and activities, characteristically cultural and intangible: proposals in which the classic observant tourist yields place to the active modern tourist. Argentine people, as owner of this culture, is displayed with diverse levels of exhibition in the official tourist communication.
\end{abstract}

Key words: cultural diversity - social inclusion - tourist destiny.

Resumo: Este trabalho explora as particularidades da diversidade no marco do turismo e as singularidades do caso argentino. O turismo se materializa na relação entre indivíduos e os sistemas socionaturais que visita temporariamente. Nesta relação, o turista se vincula com os diversos aspectos do destino turístico: naturais, sociais, artificiais, culturais, políticos, econômicos. O crescente posicionamento argentino como destino turístico implica o aporto de novos grupos significativos: realidade inédita que supõe renovadas reflexões sobre multiculturalidade. Assim mesmo, os visitantes vinculam-se com os habitantes do destino em general e, em forma direta, com as pessoas que trabalham neste setor, papéis que implicam uma inclusão social determinada.

Além disso, a preeminência clássica dos atrativos turísticos tradicionais (naturais e culturais tangívels, geralmente monumentais) está deixando espaço a outros atrativos e atividades, caracteristicamente culturais e intangíveis: propostas nas que o turista observador clássico deixa lugar ao turista ativo moderno. O povo argentino, portador dessa cultura e parte do atrativo, é apresentado com diversos níveis de exposição na comunicação turística oficial.

Palavras chave: destino turístico - inclusão social - multiculturalidade.

${ }^{*}$ Postgrado en Turismo Cultural (Universitat de Barcelona). Master di Specializzazione in Turismo (Scuola Internazionale di Scienze Turistiche y Organización Mundial del Turismo). Licenciado en Turismo (Universidad Champagnat). Docente Universitario. 